\title{
Análise de Desempenho de Possíveis Alternativas para o Canal de Retorno do Sistema Brasileiro de TV Digital
}

\author{
Monique T. F. da Silva ${ }^{1}$, Márcio J. C. Lima ${ }^{2}$ e Daniel C. Cunha ${ }^{1}$
}

\begin{abstract}
Resumo-Este trabalho apresenta uma análise de duas tecnologias candidatas (rede de acesso ADSL e rede PLC) ao canal de retorno do sistema de TV Digital no Brasil, considerando os principais efeitos nocivos de cada canal de comunicação. Curvas de probabilidade de erro de bit, obtidas por simulação computacional, são apresentadas, considerando a escolha da técnica de transmissão OFDM e valores típicos de ruído impulsivo para cada canal.
\end{abstract}

Palavras-Chave-TV Digital, ADSL, PLC, canal de retorno, interatividade.

Abstract - This paper presents an analysis of two candidate technologies (ADSL access network and network PLC) to the return channel of the Brazilian Digital TV System, considering the main adverse effects of each communication channel. Curves of bit error probability, obtained by computer simulation, are presented considering the choice of the OFDM technique transmission and typical values of impulsive noise for each channel.

Keywords-Digital TV, PLC channel, ADSL channel, return channel, interactivity.

\section{INTRODUÇÃO}

Com as primeiras transmissões da TV digital em dezembro de 2007 na cidade de São Paulo, o Sistema Brasileiro de TV Digital (SBTVD) deu início a um processo revolucionário na história da televisão brasileira. Este novo sistema foi concebido não apenas para possibilitar o envio de imagens de melhor qualidade e definição, mas também para permitir a inclusão social e digital da população. Para que isso seja possível, o SBTVD precisa oferecer interatividade aos seus usuários, ou seja, o sistema precisa permitir que os usuários interajam com a emissora. Esta característica permitirá aos provedores de conteúdo explorar uma diversidade de serviços, e.g, possibilitar ao usuário a escolha do conteúdo que deseja assistir, mas principalmente dará a oportunidade ao usuário de ter acesso à Internet por meio do aparelho de televisão.

Para que a interatividade do SBTVD seja implementada, é necessário que haja comunicação bidirecional entre a emissora e o usuário, diferente do sistema tradicional de televisão analógica. Neste contexto, o canal de comunicação entre o usuário do sistema e a emissora recebe a denominação de canal de retorno [1]. Basicamente, o canal de retorno é a tecnologia de rede que permite que a informação enviada pelo usuário chegue à emissora. Atualmente, existem diversas tecnologias candidatas para implementação do canal de retorno do SBTVD, dentre elas, as redes de acesso ADSL (do inglês, Asymmetrical Digital Subscriber Line), as redes sem fio e

1 Núcleo de Pesquisa em Telecomunicações, POLI, Universidade de Pernambuco (UPE), Recife-PE, Brasil.

2 Grupo de Pesquisa em Comunicações, Departamento de Eletrônica e Sistemas, Universidade Federal de Pernambuco (UFPE), Recife-PE, Brasil.

E-mails: moniquetfs@ gmail.com, marcio.j.c.lima@gmail.com e dccunha@upe.poli.br. a rede de distribuição elétrica (PLC, do inglês, Powerline Communications).

Este trabalho realiza uma análise de desempenho, através de simulações computacionais, de duas possíveis alternativas para o canal de retorno do SBTVD, quais sejam, a rede de acesso ADSL e a rede PLC, tendo em vista a infraestrutura preexistente em ambos os casos. Na seção II, os modelos matemáticos dos canais estudados são apresentados. Na Seção III, resultados de simulação são expostos. Uma comparação entre o desempenho da técnica de transmissão OFDM (do inglês, Orthogonal Frequency Division Multiplexing) para os dois canais é realizada. Por fim, na seção IV, são apresentadas as conclusões e as perspectivas de trabalhos futuros.

\section{MODELOS DOS CANAIS ESTUDADOS}

A Fig. 1 representa o modelo generalizado de um canal de comunicação, em que $s_{j}$ é o sinal transmitido, $H(f)$ é a função transferência do canal, $n_{j}$ é o ruído aditivo e $r_{j}$, o sinal na entrada do receptor.

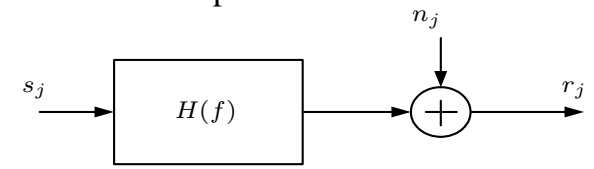

Fig. 1. Modelo generalizado de um canal de comunicação.

O estudo foi iniciado com o canal PLC, cujo modelo matemático adotado foi descrito por Zimmermann e Dostert, em [2]. Neste modelo, são considerados o efeito de multipercurso, proveniente do mau casamento de impedâncias existente ao longo da rede elétrica (pontos de derivação, emendas etc), e a atenuação, devido à variação da frequência e às dimensões do cabo. Com isso, a função de transferência do canal PLC é dada pela expressão

$$
H_{\mathrm{PLC}}(f)=\sum_{i=1}^{N} g_{i} \cdot e^{-\left(a_{0}+a_{1} f^{k}\right) d_{i}} \cdot e^{-j 2 \pi f \frac{d_{i}}{v_{p}}}
$$

em que $g_{i}$ é o termo de ponderação que representa o produto entre a reflexão e a transmissão do sinal no $i$-ésimo caminho, $a_{0}$ e $a_{1}$ são os parâmetros de atenuação, $k$ é o expoente do fator de atenuação (geralmente entre 0,5 e 1,0$), v_{p}$ é a velocidade de propagação do sinal e $d_{i}$ é o comprimento do $i$-ésimo caminho entre transmissor e receptor. A Fig. 2(a) ilustra a função de transferência do canal PLC.

O segundo canal abordado neste trabalho foi o canal ADSL, cujo modelo foi definido em [3] e cuja função de transferência é dada pela equação

$$
H_{\mathrm{ADSL}}(f)=\sqrt{e^{-2 \mathrm{~A}_{\mathrm{ch}}\left(f^{1 / 2}\right) d}},
$$

em que $f$ é a frequência dada em $\mathrm{Hz}, d$ é a distância entre 
transmissor e receptor dada em $\mathrm{km} \mathrm{e} \mathrm{A}_{\mathrm{ch}}$, uma constante que depende do diâmetro do par metálico utilizado. Cabe ressaltar que, diferentemente do canal PLC, o modelo do canal ADSL não contempla o efeito de multipercurso. A Fig. 2(b) ilustra a função de transferência do canal ADSL.
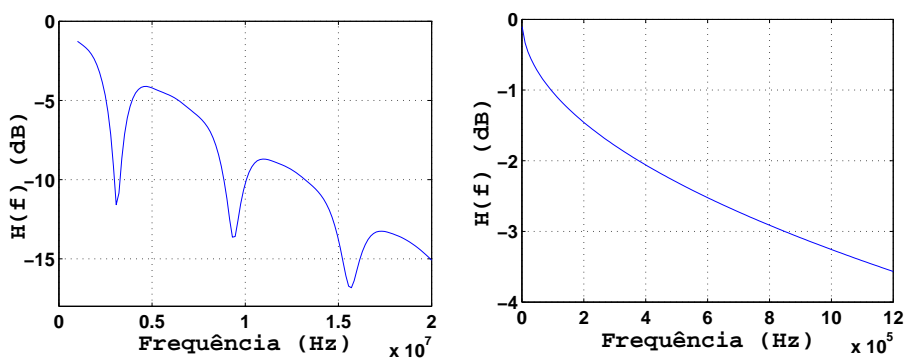

Fig. 2. (a) Função de transferência do canal PLC $(0,5-20 \mathrm{MHz})$. (b) Função de transferência do canal ADSL $(0,4-1,2 \mathrm{MHz})$.

Para ambos os canais, serão considerados dois tipos de ruídos aditivos, quais sejam, o ruído Gaussiano branco e o ruído impulsivo assíncrono. O ruído Gaussiano branco está presente em toda a faixa de frequências, enquanto o ruído impulsivo assíncrono é decorrente de transientes de tensão elétrica na rede. No canal PLC, os transientes ocorrem devido ao acionamento de equipamentos elétricos, tais como motores e lâmpadas. Já no canal ADSL, o ruído impulsivo pode ser ocasionado, e.g., pelos sinais de chamada do sistema telefônico. Desta maneira, o ruído aditivo considerado neste trabalho é dado pela expressão

$$
n_{j}=w_{j}+b_{j} g_{j}
$$

em que $w_{j}$ é o ruído Gaussiano de média zero e variância $\sigma_{w}^{2}$, $b_{j}$ é uma variável aleatória de Bernoulli de parâmetro $p$ e $g_{j}$ é o ruído Gaussiano de média zero e variância $\sigma_{g}^{2}=\gamma \sigma_{w}^{2}$ [4]. Portanto, o ruído impulsivo é caracterizado pela probabilidade de ocorrência e intensidade dos impulsos, dadas por $p$ e $\gamma$ respectivamente.

\section{RESULTADOS DE SIMULAÇÃO}

Para as simulações realizadas no canal PLC, consideramos $N=4$ caminhos de propagação, cujos parâmetros já descritos foram extraídos de [2]. Para o canal ADSL, foi considerada a utilização do cabo CT-APL-40, que possui de 200 a 3600 pares metálicos e constante $\mathrm{A}_{\mathrm{ch}}=3,4785 \times 10^{-3} \mathrm{~km}^{-1} \mathrm{~Hz}^{-1 / 2}$ [3]. Em ambos os canais, foi utilizada a técnica de transmissão OFDM e para cada subportadora, a modulação 4-QAM (do inglês, Quadrature Amplitude Modulation) foi empregada. Além disso, foi assumida a distância $d=200 \mathrm{~m}$ para os dois cenários, sendo este valor no caso do canal PLC, a distância do caminho direto entre transmissor e receptor.

A Fig. 3 e a Fig. 4 ilustram as curvas de probabilidade de erro de bit $\left(P_{b}\right)$ versus razão sinal-ruído (RSR) em dB, obtidas para os canais ADSL e PLC, respectivamente, em que o número de subportadoras utilizadas foi igual a 512, 1024, 2048 e 4096. Para o canal ADSL, foi adotado um ruído impulsivo de parâmetros $p=0,004$ e $\gamma=20$ [5], enquanto que para o canal PLC, os parâmetros utilizados foram $p=0,01$ e $\gamma=20$.

Observa-se então que, para uma $P_{b}=10^{-3}$, por exemplo, a utilização de 512 subportadoras no canal PLC proporcionou uma redução de aproximadamente $30 \mathrm{~dB}$ quando comparada ao canal ADSL para o mesmo número de subportadoras. Uma possível justificativa para tal fato é que as subportadoras, no canal PLC, são distribuídas ao longo de uma maior faixa de frequências $(0,5-20 \mathrm{MHz})$, o que não acontece para o canal

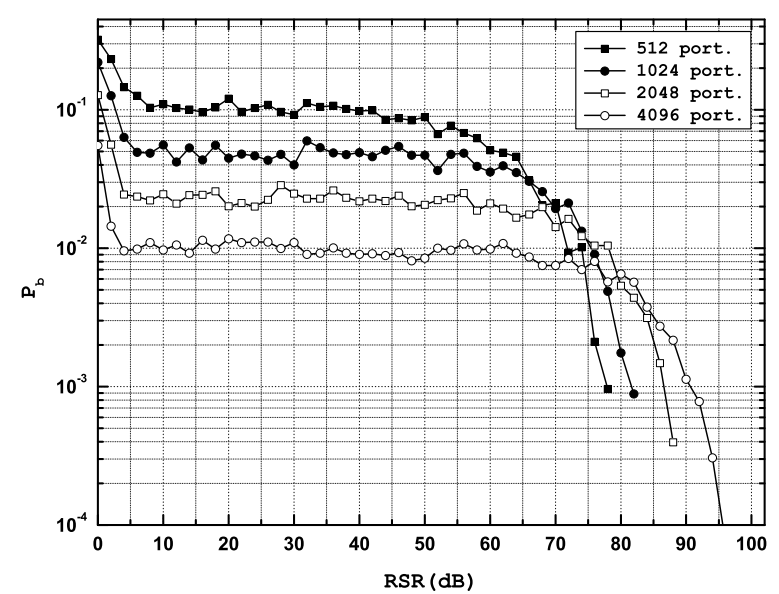

Fig. 3. Probabilidade de erro de bit versus relação sinal-ruído para o canal ADSL com ruído Gaussiano branco e ruído impulsivo com $p=0,004$ e $\gamma=20$, para 512, 1024, 2048 e 4096 subportadoras OFDM.

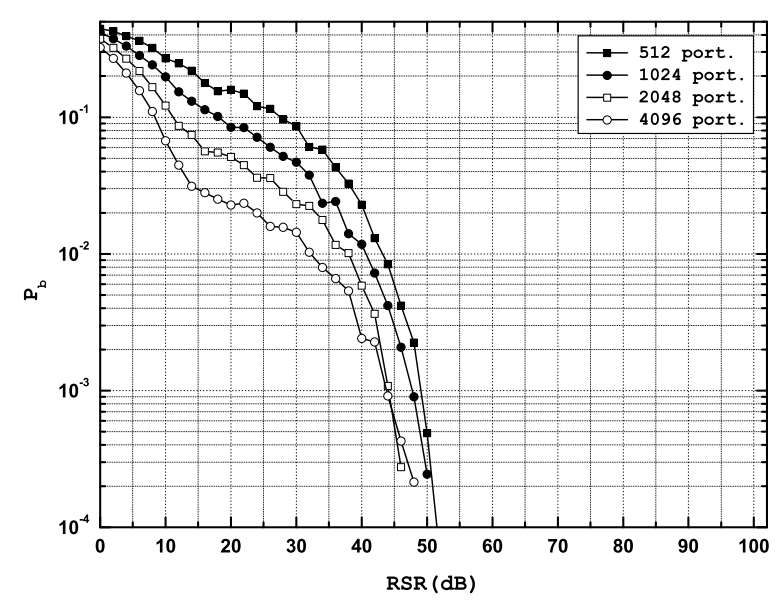

Fig. 4. Probabilidade de erro de bit versus relação sinal-ruído para o canal PLC com ruído Gaussiano branco e ruído impulsivo com $p=0,01$ e $\gamma=20$, para 512, 1024, 2048 e 4096 subportadoras OFDM.

ADSL (0, 4-1, 2 MHz). Logo, a distância entre subportadoras é menor para o canal ADSL, sendo mais susceptível a ruído entre subportadoras adjacentes.

\section{CONCLUSÕES}

As curvas obtidas por simulação evidenciam que o canal PLC apresenta um melhor desempenho quando comparado ao ADSL, muito embora não se tenha considerado todos os efeitos nocivos e ruídos presentes em cada canal, e.g., diafonia, ruído colorido e impulsivo periódico.

Como perspectiva de trabalhos futuros, é sugerida uma investigação mais criteriosa no que se refere aos modelos de canais estudados, assim como aos tipos de ruídos considerados. Dessa forma, será possível contribuir para o estudo de uma alternativa viável a ser utilizada no canal de retorno do SBTVD.

\section{REFERÊNCIAS}

[1] M. S. de Alencar, Televisão Digital. 1 ed., Érica, 2007.

[2] M. Zimmermann e K. Dostert, "A Multipath Model for the Powerline Channel," IEEE Trans. on Comm., v. 50, n. 4, pp. 533-559, Abr. 2002.

[3] S. C. Monteiro, Modelo de Avaliação da Capacidade da Rede de Acesso Metálica para o Provimento de Serviços Suportados pela Tecnologia ADSL, Diss de Mestrado, Universidade de Brasília (UnB), Brasil, 2007.

[4] M. Ghosh, "Analysis of the Effect of Impulsive Noise on Multicarrier and Single Carrier QAM Systems," IEEE Trans. on Comm./, v. 44, n. 2, pp. 145-147, Fev. 1996.

[5] D. Franklin, J. Chicharo e J. Xi, "A New Channel Model for ADSL and VDSL Systems," In Proceedings of V Int. Symp. on Signal Proc. and its Applic. (ISSPA 99), Brisbane, Austrália, Maio 1999. 